\title{
A new genus of Oniscidea from South America and a phylogenetic analysis of related genera (Crustacea: Isopoda: Philosciidae)
}

\author{
Andreas Leistikow \\ Universität Bielefeld, Abteilung für Zoomorphologie und Systematik, Morgenbreede 45, D-33615 Bielefeld/ \\ Ruhr-Universität Bochum, Lehrstuhl für spezielle Zoologie, Universitätsstraße 150, D-44780 Bochum. \\ E-mail: Leiste@Biologie.Uni-Bielefeld.de
}

Keywords: Metaprosekia nodilinearis, Xiphoniscus mirabilis, Oniscidea, Philosciidae, South America, phylogeny, phylogenetic sytematics

\begin{abstract}
In a collection of terrestrial isopods from Venezuela, a distinct species was identified which does not fit any of the known genera. Therefore, a new taxon Metaprosekia gen.n. is instituted to accomodate the new species. An analysis of its morphological characters revealed a close relationship to the genus Prosekia Vandel, 1968 and allied genera. The phylogeny of this group is discussed and one of its poorly known representatives, Xiphoniscus mirabilis Vandel, 1968 is redescribed on the basis of the type material.
\end{abstract}

\section{Contents}

\begin{tabular}{lr} 
Abstract & 179 \\
Introduction & 179 \\
Systematics & 180 \\
\multicolumn{1}{c}{ Metaprosekia gen. n. } & 180 \\
$\quad$ Metaprosekia nodilinearis sp. n. & 180 \\
$\quad$ Xiphoniscus Vandel, 1968 & 186 \\
$\quad$ Xiphoniscus mirabilis sp. n. & 186 \\
Phylogeny within the Prosekia genus group & 193 \\
Acknowledgements & 196 \\
References & 196
\end{tabular}

\section{Introduction}

South America harbours a highly diverse fauna of terrestrial Isopoda, most of them are traditionally grouped in the paraphyletic family "Philosciidae“", which is defined only by plesiomorphies resulting from the similar habitus of all those species. In the light of phylogenetic systematics, the genera have to be re-examined and monophyletic groups have to be identified. The revision of several gen- era described from Venezuela, Ecuador, and Colombia by Vandel $(1952,1968$ and 1972) gave first insight in the phylogeny of philosciid genera from northwestern South America. The re-descriptions of Prosekia Vandel, 1968 (Leistikow in press, a), Erophiloscia Varidel, 1972 (Leistikow in press, b) and of a new genus from this area (Leistikow 1999a) all have revealed a remarkable similarity in the structure of the antennula. Furthermore, this type of antennula was found in the genus Andenoniscus Verhoeff, 1941, too (Leistikow 1998), although this was not noted in the original description by Verhoeff (1941). This specific shape of the antennula and further characters will be discussed in detail, and additional data on the unusual species Xiphoniscus mirabilis Vandel, 1968 will be presented based on the type series of the Muséum National d'Histoire Naturelle, Paris (NMHN).

Furthermore, a new genus will be described sharing the specific type of antennula. It was found in samplings from Venezuela. The species shows striking differences to all the above mentioned genera. Thus, a separation into its own genus is the best taxonomic approach to its phylogeny. It was found in the eastern part of Venezuela in the Cordilleras at $1500 \mathrm{~m}$ altitude. The type material is deposited in the Museum für Naturkunde der Humboldt-Universität Berlin (MNHU). Paratypes were sent to the Museum of the University of Maracay, Venezuela (MUMV) and the Museo Nacional, Rio de Janeiro, Brazil (MNRJ). 


\section{Systematics}

\section{Metaprosekia gen. $\mathrm{n}$.}

Diagnosis. - Cephalothorax with linea supra-antennalis, faint linea frontalis and lateral lobes, compound eyes consisting of about three individualised ommatidia, antennula with two divergent sets of aesthetascs, antennal flagellum three-articulate with long apical organ.

Mandible with molar penicil composed of about 4 branches, tooth formula of maxillula $4+4$ with three of the inner set cleft, lateral lobe of maxilla broader than medial, maxilliped endite without setation, small knob rostrally.

Pereiopods slender, ornamental sensory spine of carpus 1 double-fringed serrate, carpus with mediodistal tuft of setae, dactylus with short inner claw, two interungual setae and simple dactylar seta, coxal plates with sulcus marginalis and noduli laterales, all at same distance from lateral margin.

Pleopods with few lateral sensory spines on exopodite, male exopodite 1 cordiform, genital papilla with straight margins, apically obtuse. Uropod with protopodite triangular, laterally grooved, endopodite inserting proximally of exopodite. Tricorn-like setae of pleotelson with spatulate apex.

Type species. - Metaprosekia nodilinearis sp. n. (by monotypy)

Etymology. - The genus name reflects the close relationship to Prosekia with emphasis on the more derived morphology of the new species.

\section{Metaprosekia nodilinearis sp. n. (Figs. 1-5)}

Material. - Holotype: male $5 \mathrm{~mm}$, MNHU collection uncatalogised: Eastern slope of the Andes "La Campaña", $8^{\circ} 51.92^{\prime} \mathrm{N} 70^{\circ} 37.14 \mathrm{~W}$, alt. $1500 \mathrm{~m}(+-200 \mathrm{~m})$, moist forest with Araceae, Arecaceae, Melostomaceae and Orchidaceae, in mycelia under a rotten trunk, leg. 29.3.1998; Paratypes: male, female with marsupium, MUMV uncatalogised: same data as holotype; male, MNRJ uncatalogised: same data as holotype; 2 males, female with marsupium, author's collectionx same data as holotype.

Description.- Colour: Colour of examined specimen faded to yellowish brown, save light patches on coxal plates, no spotting discernible.

Cephalothorax: Linea supra-antennalis present, linea frontalis very faint, small lateral lobes, no lamina frontalis; eyes small, three ommatidia imbedded in pigment mass (Fig. 1, Ctf).

Pereion: Slender, tegument bearing scattered tricorn-like setae, coxal plates with sulcus marginalis and prominent nodulus lateralis, gland pores not discernible in light microscope. All noduli laterales inserting at same distance from lateral margin of coxal plates (Fig. 1, Cxp/Cx3).

Pleon: Retracted from pereion, pleonites 3 to 5 with adpressed neopleurae, pleotelson with straight lateral margins, about six tricorn-like setae along margin, apically spatulate (Fig. 1, Tel).

Antennula: Apical article with two sets of aesthetascs, one terminally composed of two, one medially composed of about 10 aesthetascs (Fig. 1, Anl).

Antenna: Peduncle rather stout, free article 5 somewhat swollen, flagellum three-segmented with apical organ longer than longest flagellar article, medial article with two sets of aesthetascs (Fig. 1, An2).

Mandible: Molar penicil composed of four branches, pars intermedia with few coniform setae and stout penicils, two on left and one on right side, additional penicil in examined specimen present on right mandible (Fig. 2, Mdl/r).

Maxillula: Medial endite with apical point and two weak penicils, lateral endite with $4+4$ teeth, inner set cleft save one slender tooth, lateral set broader than medial (Fig. 2, Mx1).

Maxilla: Only slightly hirsute, lateral lobe broader than medial, medial lobe with 5 cusps (Fig. 2, Mx2).

Maxilliped: Basis slender, tricorn-like setae only medially, sulcus lateralis present, palp with two setal tufts, proximal set stalked, endite without setation, caudally with prominent tooth, rostrally with small knob (Fig. 2, Mxp).

Pereiopods: Rather slender, bearing few tricornlike setae (Figs. 3/4, PE1-7), carpus of pereiopod 1 with antenna-grooming brush composed of cuticular scales, ornamental sensory spine doublefringed serrate (Fig. 3, Scl), sensory spines with two subapical tips, carpus bearing setal tuft laterodistally, dactylus with short inner claw, two interunguxal setae and simple dactylar seta (Fig. 3, Dac).

Sexual dimorphism: No obvious differences. 


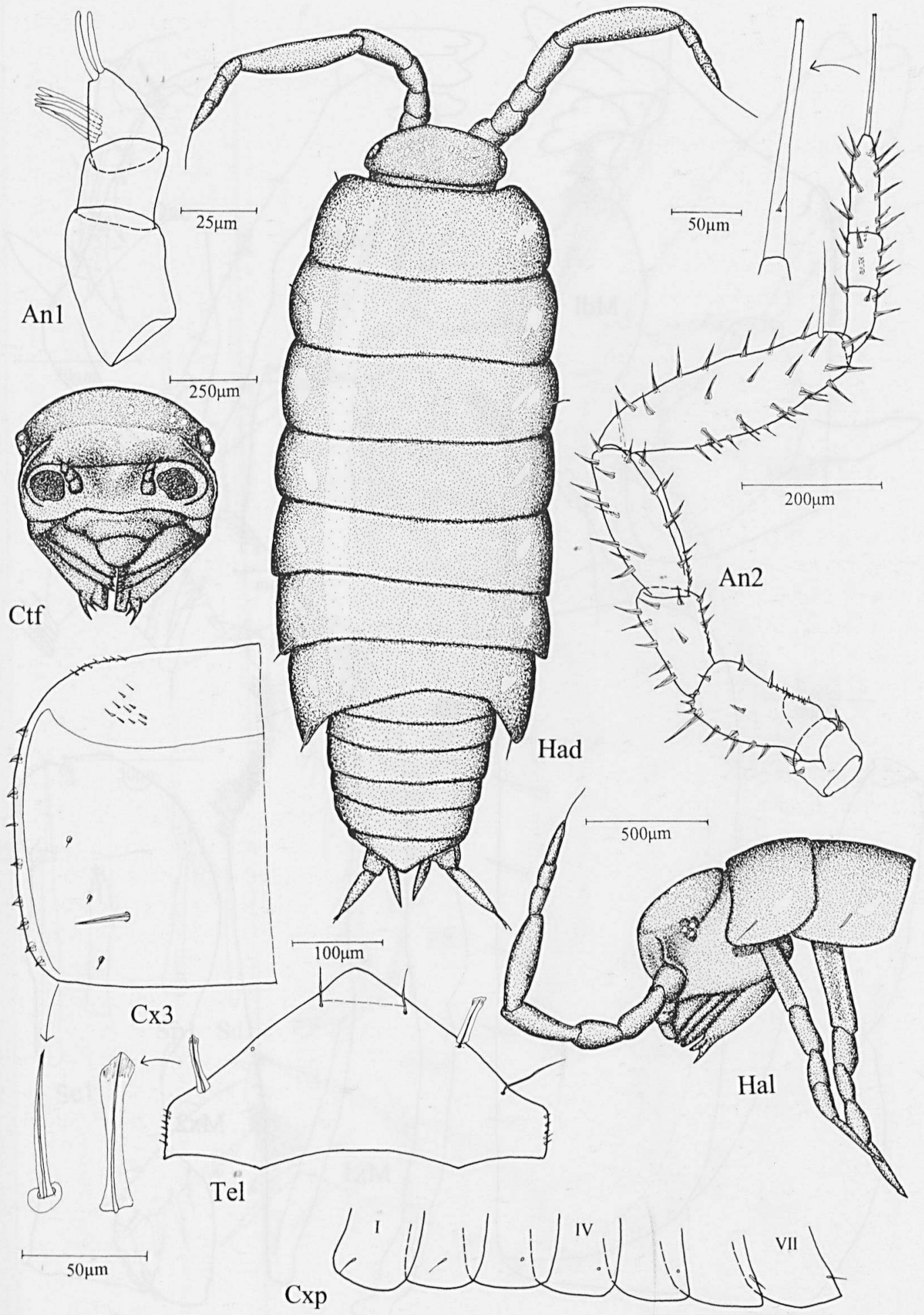

Fig. 1. Metaprosekia nodilinearis sp. n. holotype male $5 \mathrm{~mm}$. An1 antennula; An2 antenna with detail of apical organ; Ctf cephalothorax in frontal view; Cxp position of noduli laterales on coxal plates; $\mathrm{Cx} 3$ coxal plate 3 , with detail of nodulus lateralis; Had habitus in dorsal view; Hal habitus in lateral view; Tel pleotelson with detail of sensory spine. 


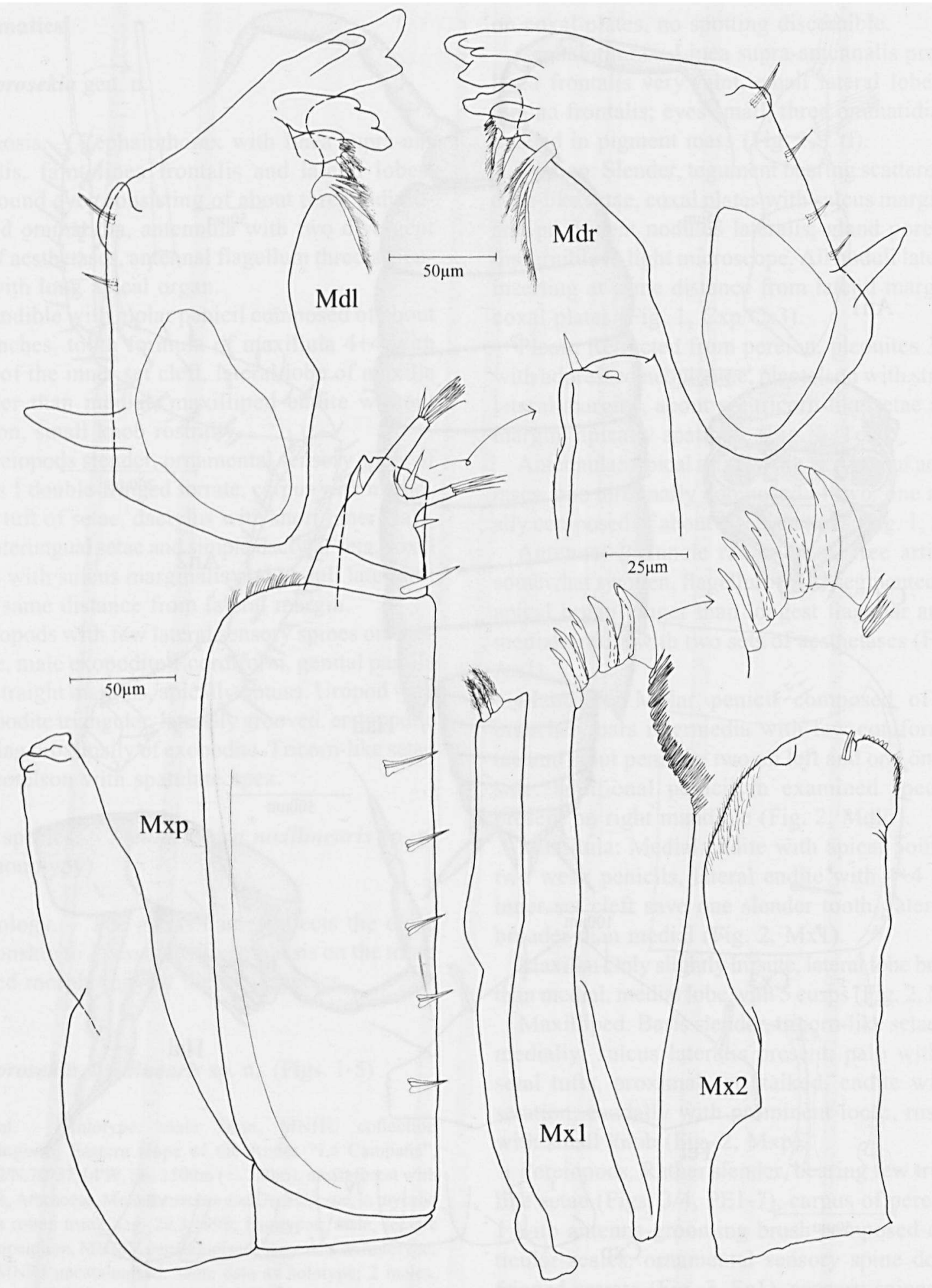

Fig. 2. Metaprosekia nodilinearis $\mathrm{sp}$. $\mathrm{n}$. holotype male $5 \mathrm{~mm}$. Mdl/ $\mathrm{r}$ left and right mandible; Mxp maxilliped with detail of endite in rostral view; Mx1 maxillula with detail of apex of lateral endite; Mx2 maxilla. 


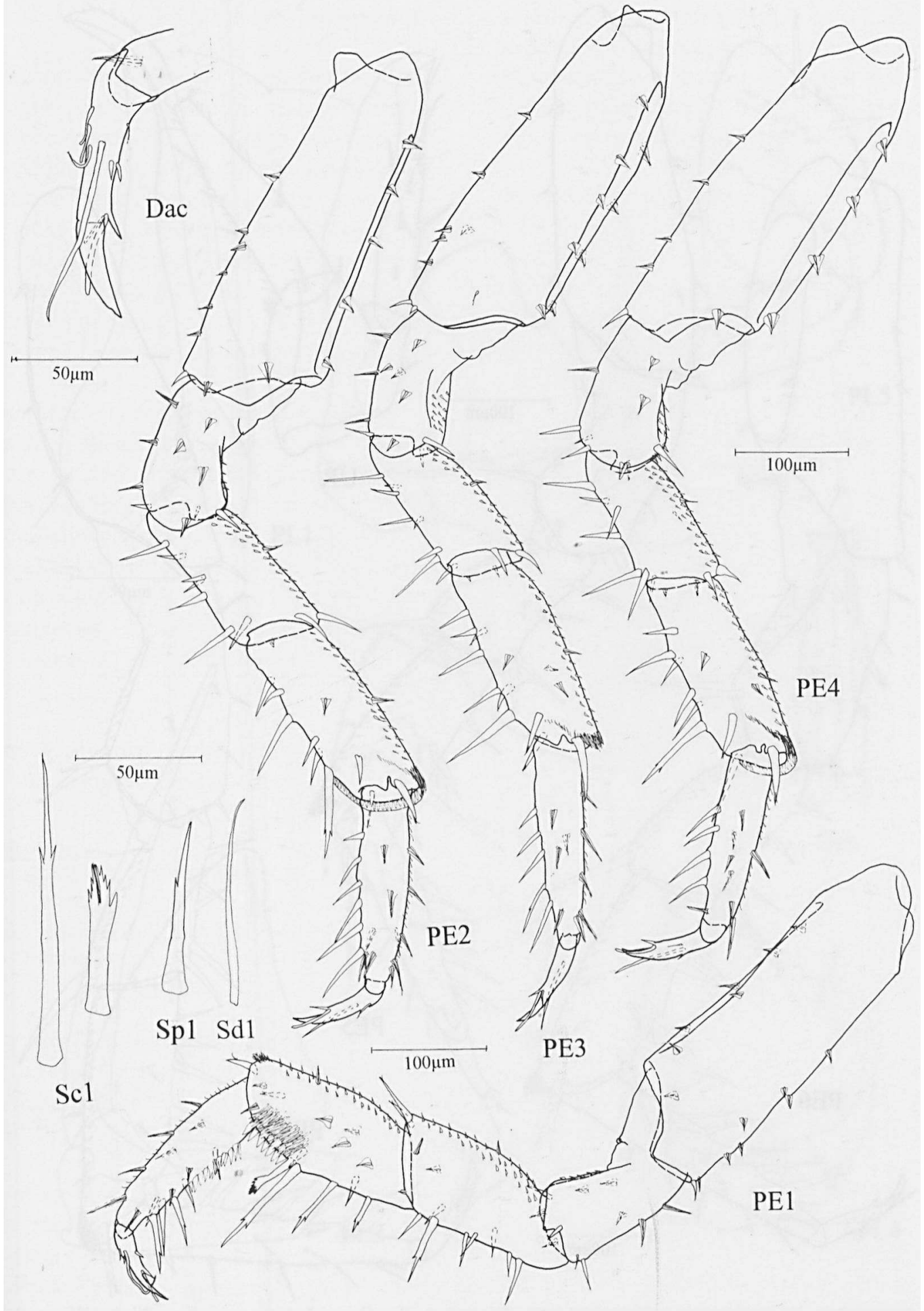

Fig. 3. Metaprosekia nodilinearis sp. $\mathrm{n}$. holotype male $5 \mathrm{~mm}$. Dač dactylus in rostral view; PE 1-4 pereiopods lin rostral view, 2-4 in caudal view; Scl ornamental sensory spine and longest sensory spine of carpus 1; Sd1 dactylar seta of dactylus 1; Spl distal sensory spine of propus 1. 


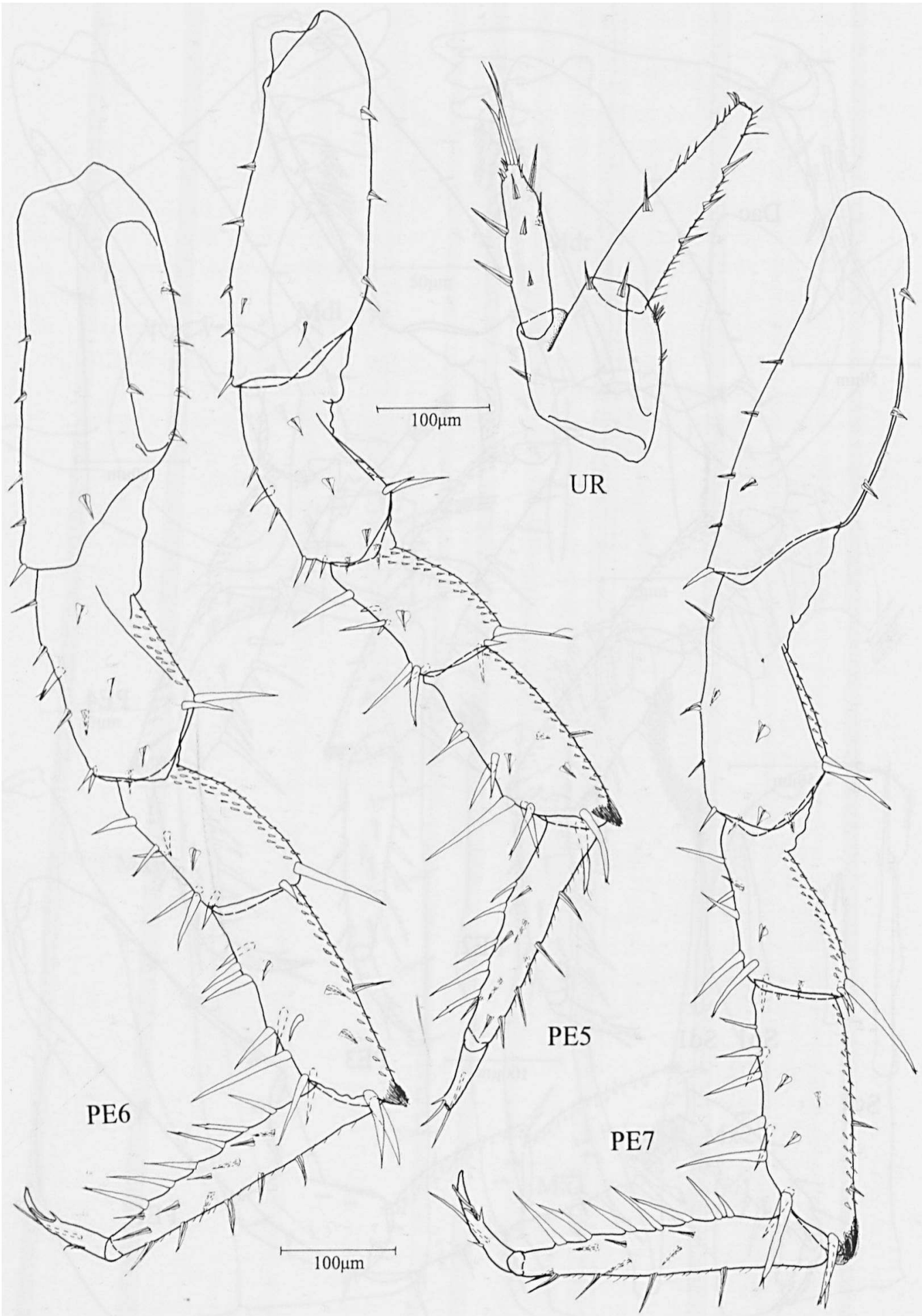

Fig. 4. Metaprosekia nodilinearis sp. n. holotype male $5 \mathrm{~mm}$. PE5-7 pereiopods 5-7 in caudal view; UR uropod. 

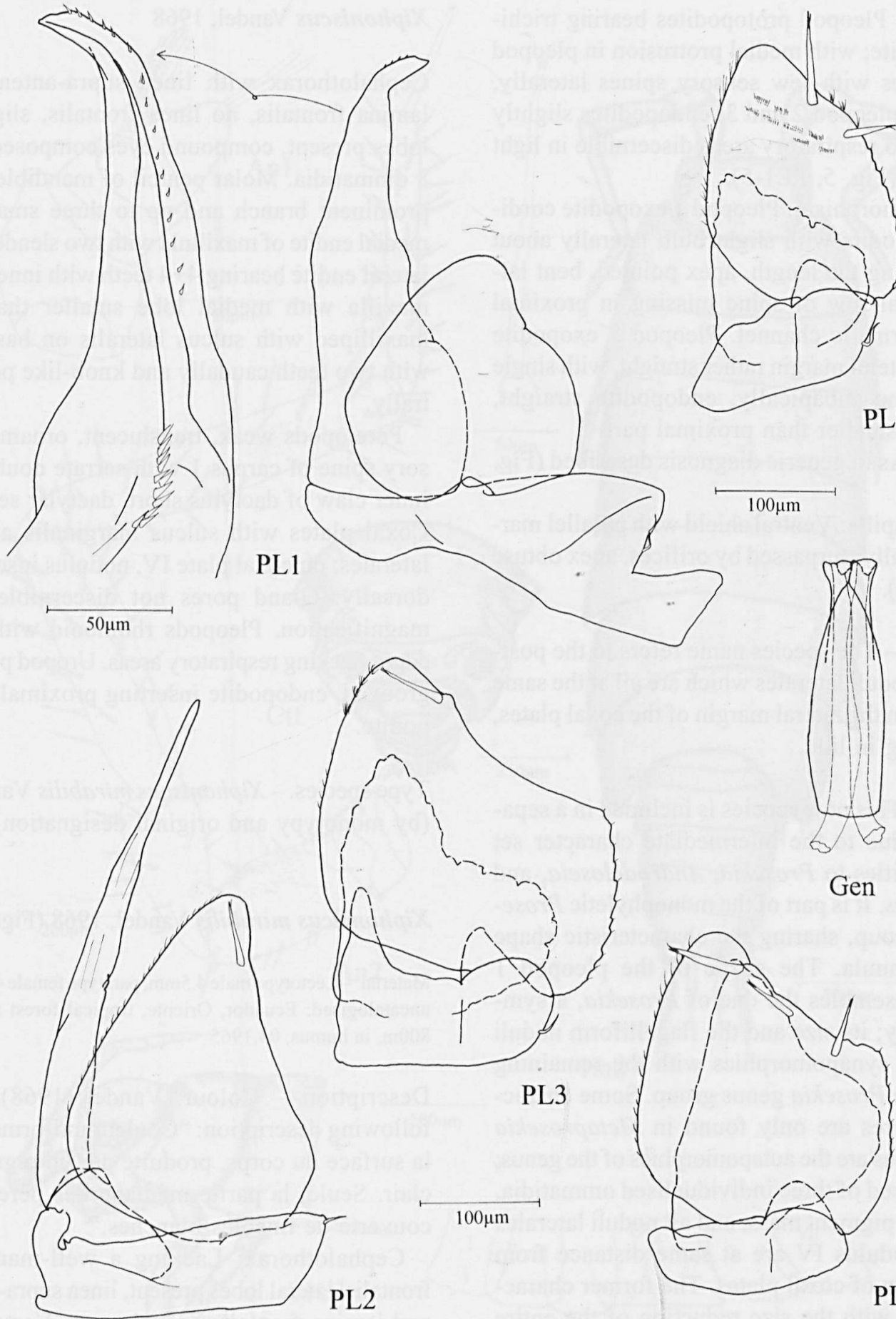

PL5

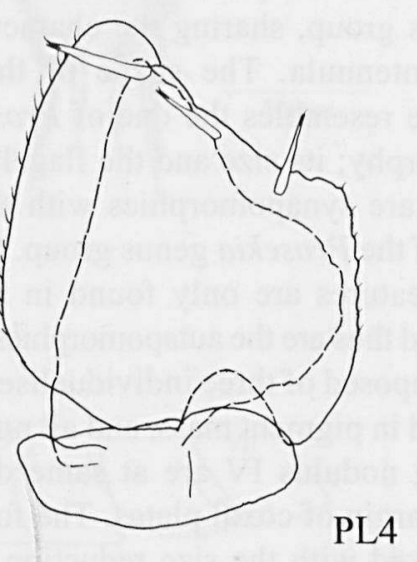

Fig. 5. Metaprosekia nodilinearis sp. n. male $5 \mathrm{~mm}$. Gen genital papilla; PL $1-5$ pleopods 1 to 5 with detail of pleopod 1 endopod in caudal view. 
Pleopods: Pleopod protopodites bearing trichiform epipodite; with medial protrusion in pleopod 3, exopodites with few sensory spines laterally, only one in pleopod 2 and 3 , endopodites slightly triangular, no respiratory areas discernible in light microscope (Fig. 5, PL1-5).

Sexual dimorphism: Pleopod 1 exopodite cordiform, endopodite with slight bulb laterally about half way along the length, apex pointed, bent laterally, caudal row of spine missing in proximal third of spermatic channel. Pleopod 2 exopodite triangular, lateral margin rather straight, with single sensory spine subapically, endopodite straight, apical third smaller than proximal part.

Uropod: As in generic diagnosis described (Fig. 4, UR).

Genital papilla: Ventral shield with parallel margins proximally, surpassed by orifices, apex obtuse (Fig. 5, Gen).

Etymology. - The species name refers to the position of the noduli laterales which are all at the same distance from the lateral margin of the coxal plates, thus standing in line.

Remarks. - This new species is included in a separate genus due to the intermediate character set with similarities to Prosekia, Androdeloscia, and Andenoniscus. It is part of the monophyletic Prosekia genus group, sharing the characteristic shape of the antennula. The shape of the pleopod 1 exopodite resembles the one of Prosekia, a symplesiomorphy; its size and the flagelliform noduli laterales are synapomorphies with the remaining genera of the Prosekia genus group. Some characteristic features are only found in Metaprosekia gen. $n$. and thus are the autapomorphies of the genus: Eyes composed of three individualised ommatidia, imbedded in pigment mass, and all noduli laterales including nodulus IV are at same distance from lateral margin of coxal plates. The former character is linked with the size reduction of the entire group, but is here extremely marked. All the other genera have about 8 ommatidia which are standing closely together and the corneae forming a capsule, whereas in Metaprosekia, the ommatidia are separated by pigment masses and the corneae are not connected to each other.
Xiphoniscus Vandel, 1968

Cephalothorax with linea supra-antennalis and lamina frontalis, no linea frontalis, slight lateral lobes present, compound eyes composed of about 8 ommatidia. Molar penicil of mandible with one prominent branch and up to three smaller ones, medial endite of maxillula with two slender penicils, lateral endite bearing $4+4$ teeth with inner set cleft, maxilla with medial lobe smaller than lateral, maxilliped with sulcus lateralis on basis, endite with two teeth caudally and knob-like penicil rostrally.

Pereiopods weak, translucent, ornamental sensory spine of carpus 1 with serrate double-fringe, inner claw of dactylus short, dactylar seta simple. Coxal plates with sulcus marginalis and noduli laterales; on coxal plate IV, nodulus inserted more dorsally. Gland pores not discernible at $400 x$ magnification. Pleopods rhomboid with rounded edges, lacking respiratory areas. Uropod protopodite grooved, endopodite inserting proximally of exopodite.

Type species. - Xiphoniscus mirabilis Vandel, 1968 (by monotypy and original designation)

Xiphoniscus mirabilis Vandel, 1968 (Figs. 6-11)

Material -Lectotype male 4.5mm, paratype female $4 \mathrm{~mm}$ MNHN uncatalogised: Ecuador, Oriente, tropical forest at Puyo, alt. $800 \mathrm{~m}$, in humus, 04.1965

Description. - Colour: Vandel (1968) gave the following description: "Couleur uniforme sur toute la surface du corps, produite par un pigment brun clair. Seule, la partie médiane des péreonites est couverte de linéoles blanches."

Cephalothorax: Lacking a well-marked linea frontalis, lateral lobes present, linea supra-antennalis and lamina frontalis conspicuous. Vertex arched, covered with long tricorn-like setae, compound eyes composed of about 8 ommatidia (Fig. 6, Ctf).

Pereion: Surface of pereionites shiny, with microscopical cuticular structure, rather densely covered with tricorn-like setae, coxal plates with sulcus marginalis, noduli laterales flagelliform, more 


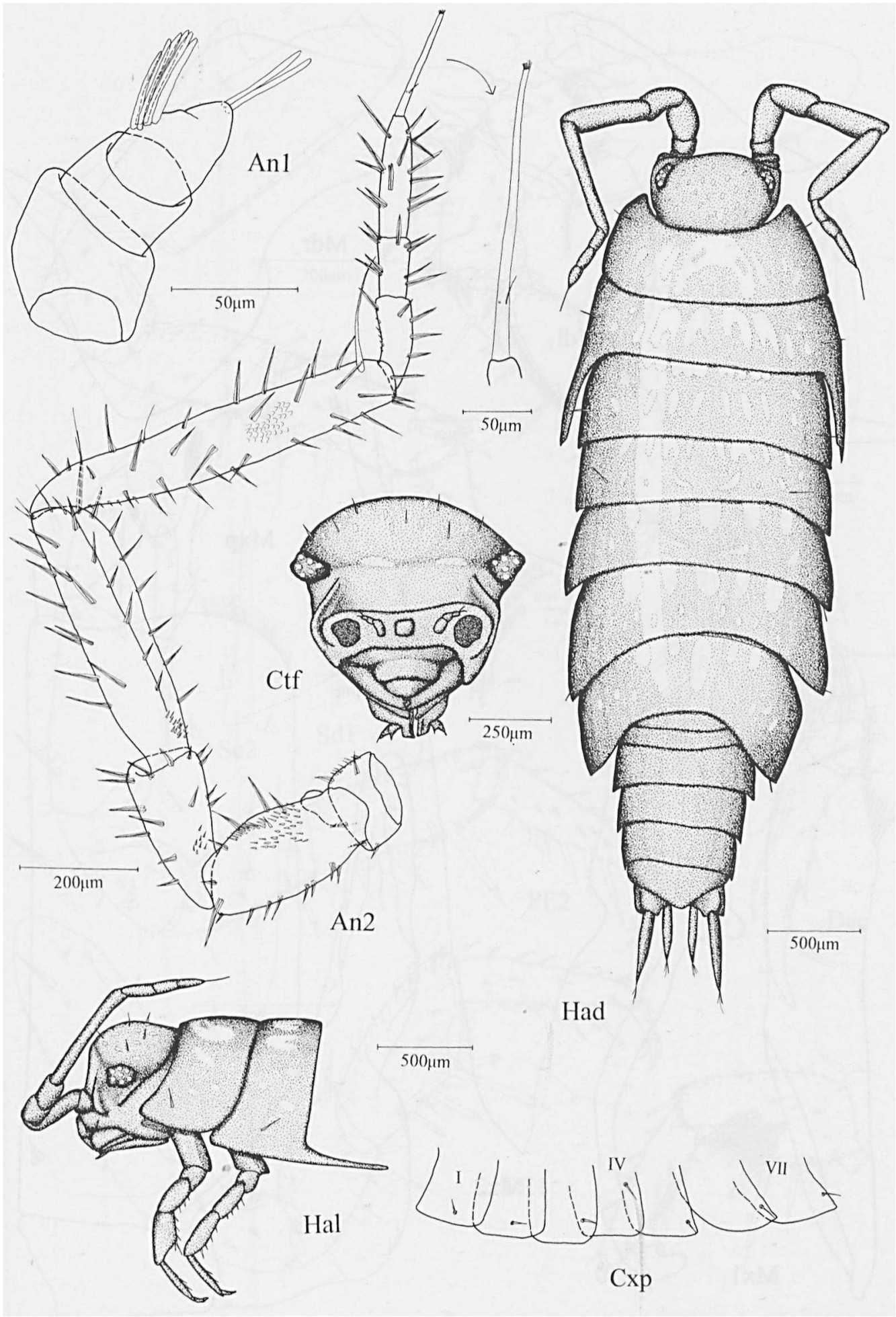

Fig. 6. Xiphoniscus mirabilis Vandel, 1968 Lectotype male 4.5m̄m. An1 antennula; An2 antenna; Ctf cephalothorax in frontal view;

$\Gamma_{x p}$ position of noduli laterales on coxal plates; Had habitus in dorsal view; Hal habitus in lateral view; Tel pleotelson. 


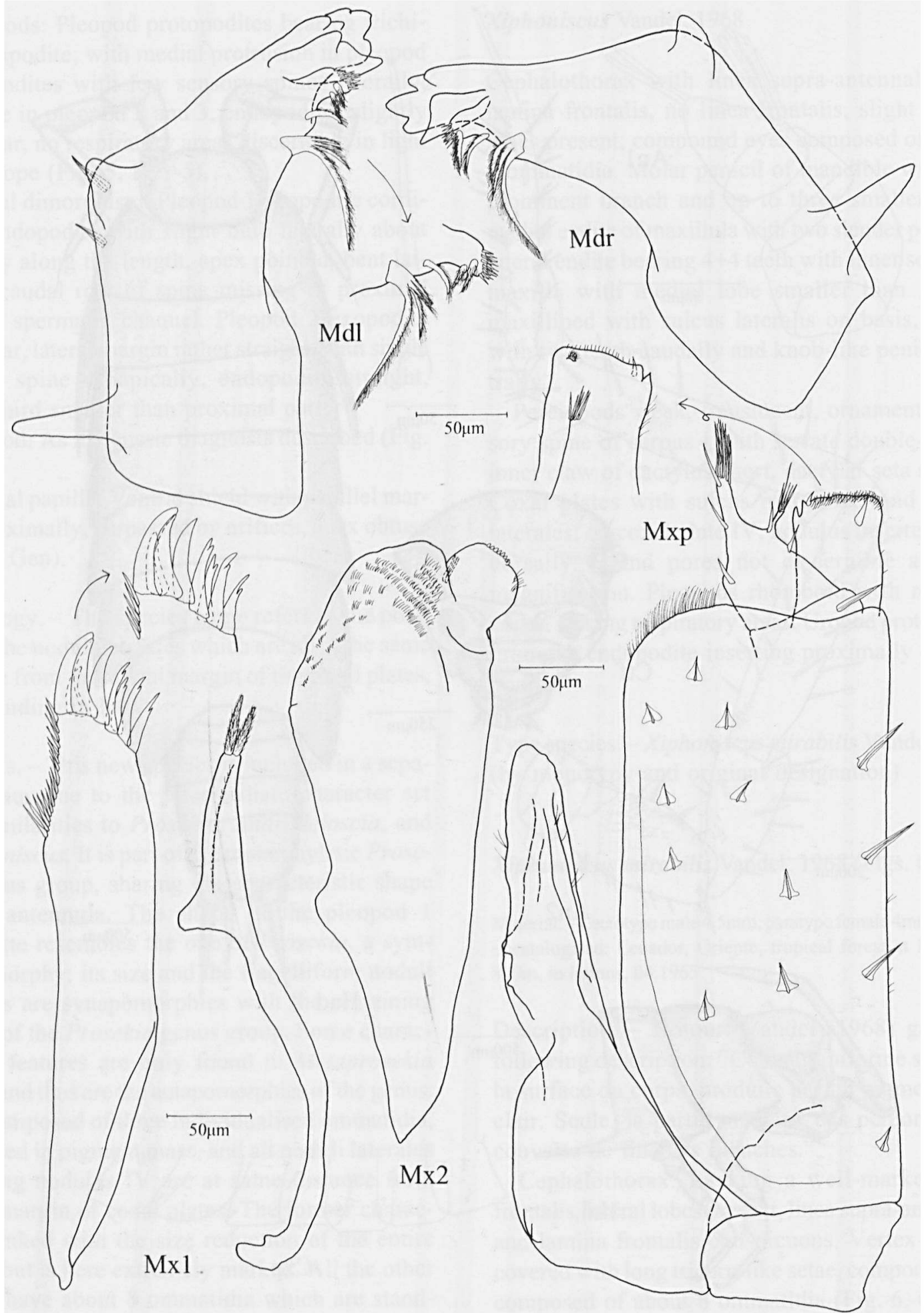

Fig. 7. Xiphoniscus mirabilis Vandel, 1968 Lectotype male 4.5mm. Mdl/r left and right mandible with detail of pars intermedia of left mandible; Mxp maxilliped with detail of endite in rostral view; Mxl maxillula with detail of apex of lateral endite; Mx2 maxilla. 


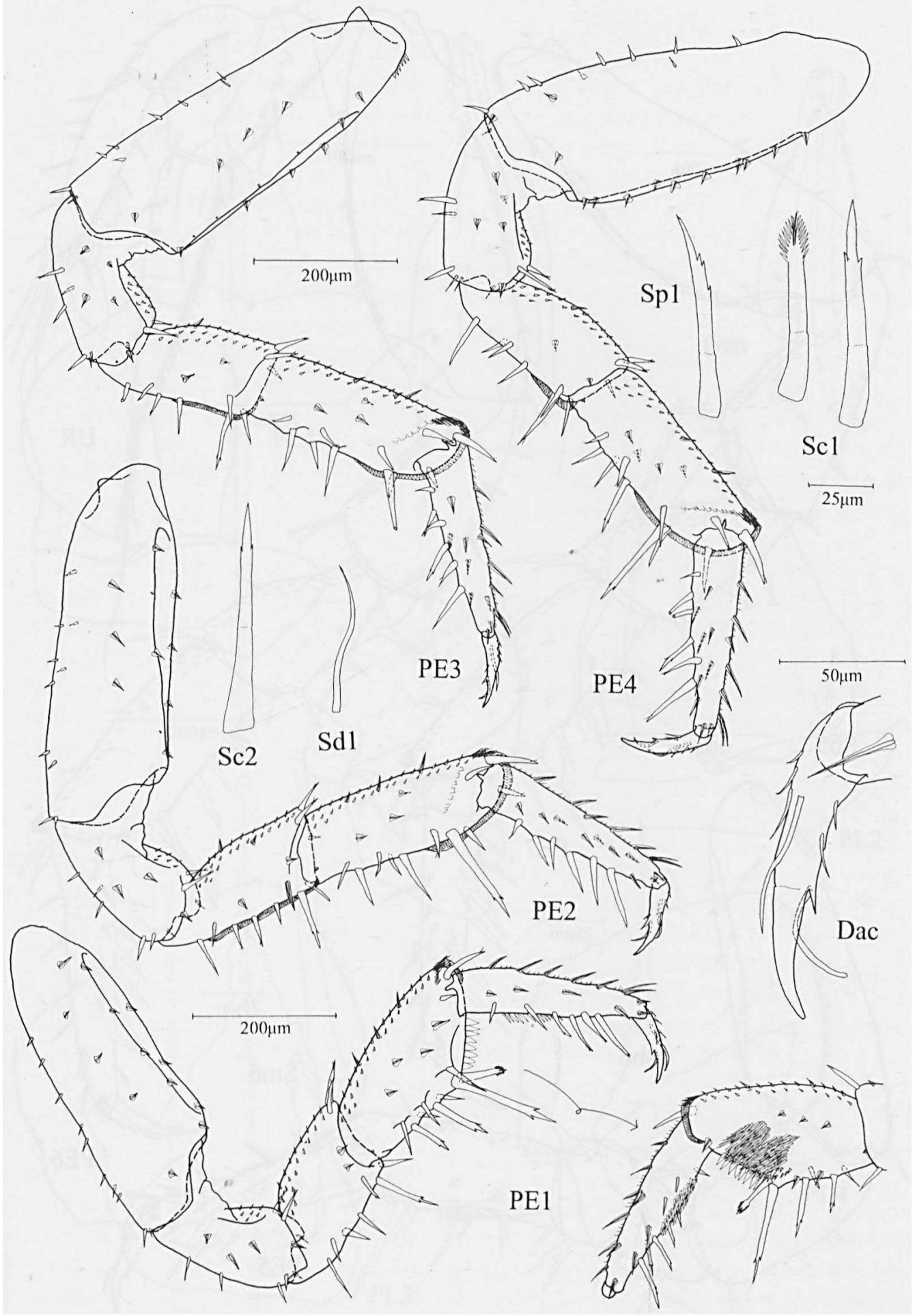

Fig. 8. Xiphoniscus mirabilis Vandel, 1968 Lectotype male 4.5mm. Dac dactylus in rostral view; PE1-4 pereiopods 1-4 caudal view, detail of carpus 1 in rostral view; Scl ornamental sensory spine and medial sensory spine of carpus 1; Sc2 sensory spine of carpus 2; $\mathrm{Sdl}$ dactylar seta of dactylus 1; Spl distal sensory spine of propus 1 . 


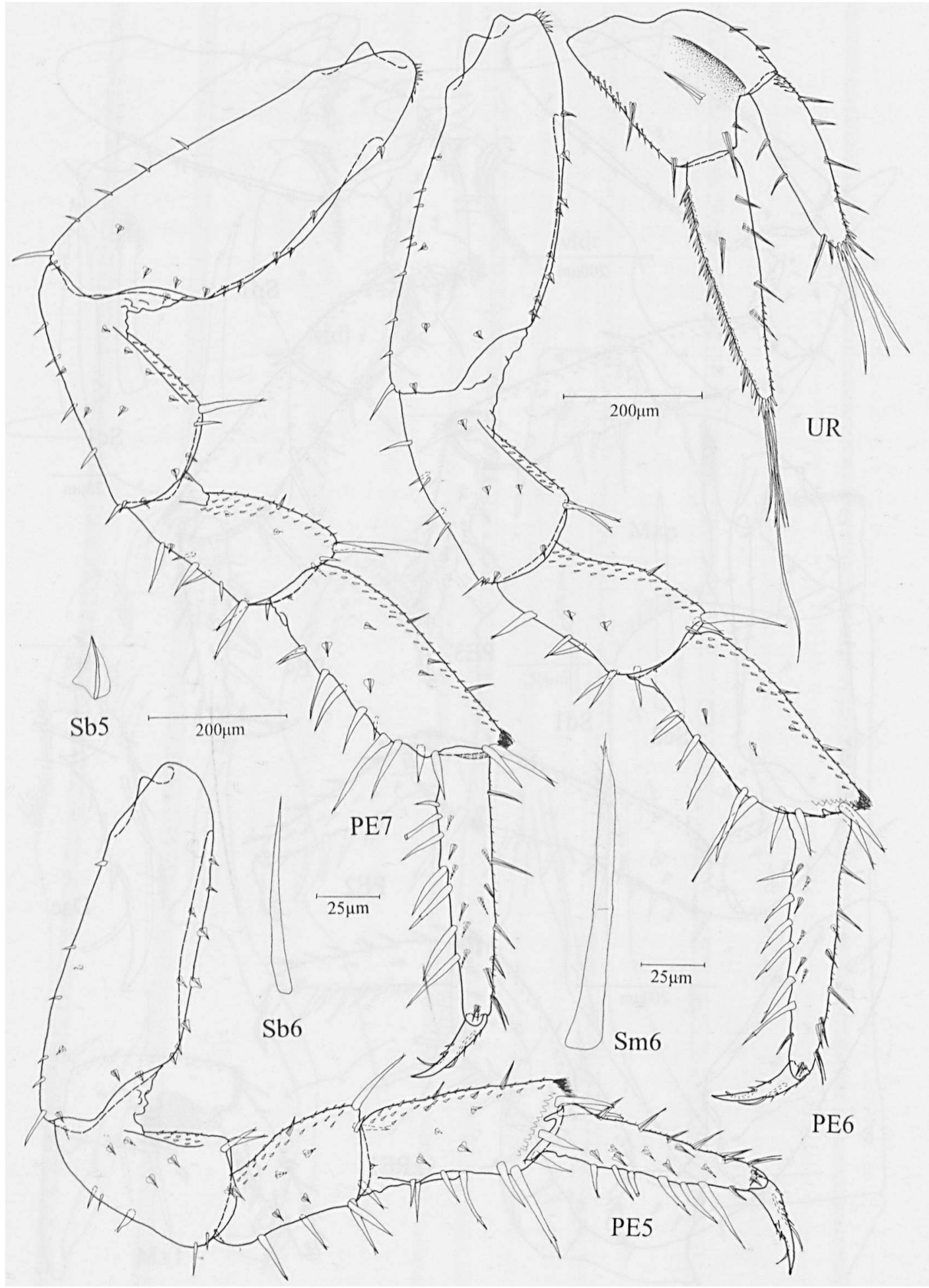

Fig. 9. Xiphoniscus mirabilis Vandel, 1968 Lectotype male $4.5 \mathrm{~mm}$. PE5-7 pereiopods 5-7 in caudal view; Sb5 tricorn-like seta of basis 5; Sb6 sensory spine of basis 6; $\mathrm{Sm} 7$ sensory spine of merus 7; UR uropod. 


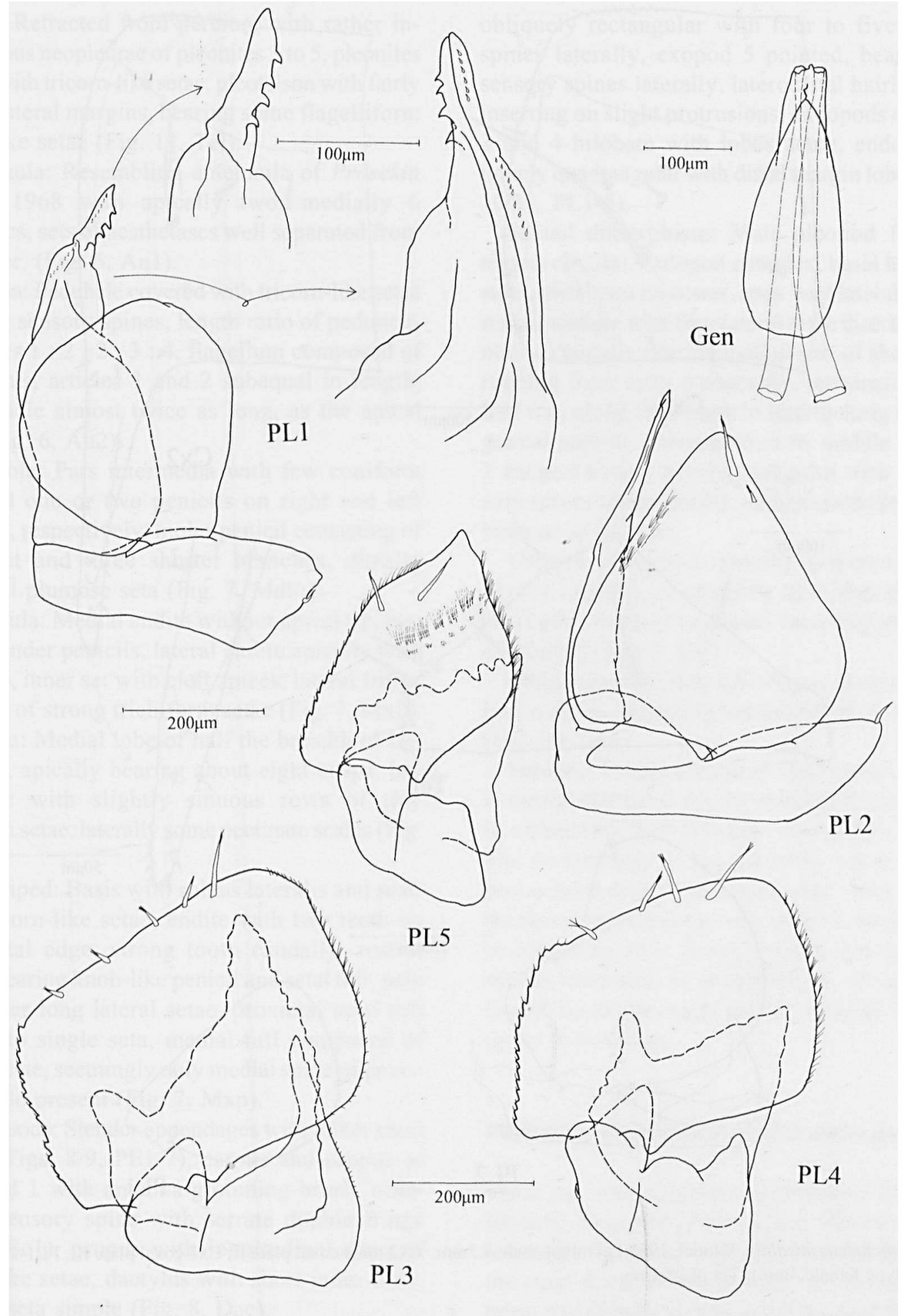

Fig. 10. Xiphoniscus mirabilis Vandel, 1968 Lectotype male 4.5mm. Gen genital papilla; PL1-5 pleopods 1 to 5, with details of endopod 1. 

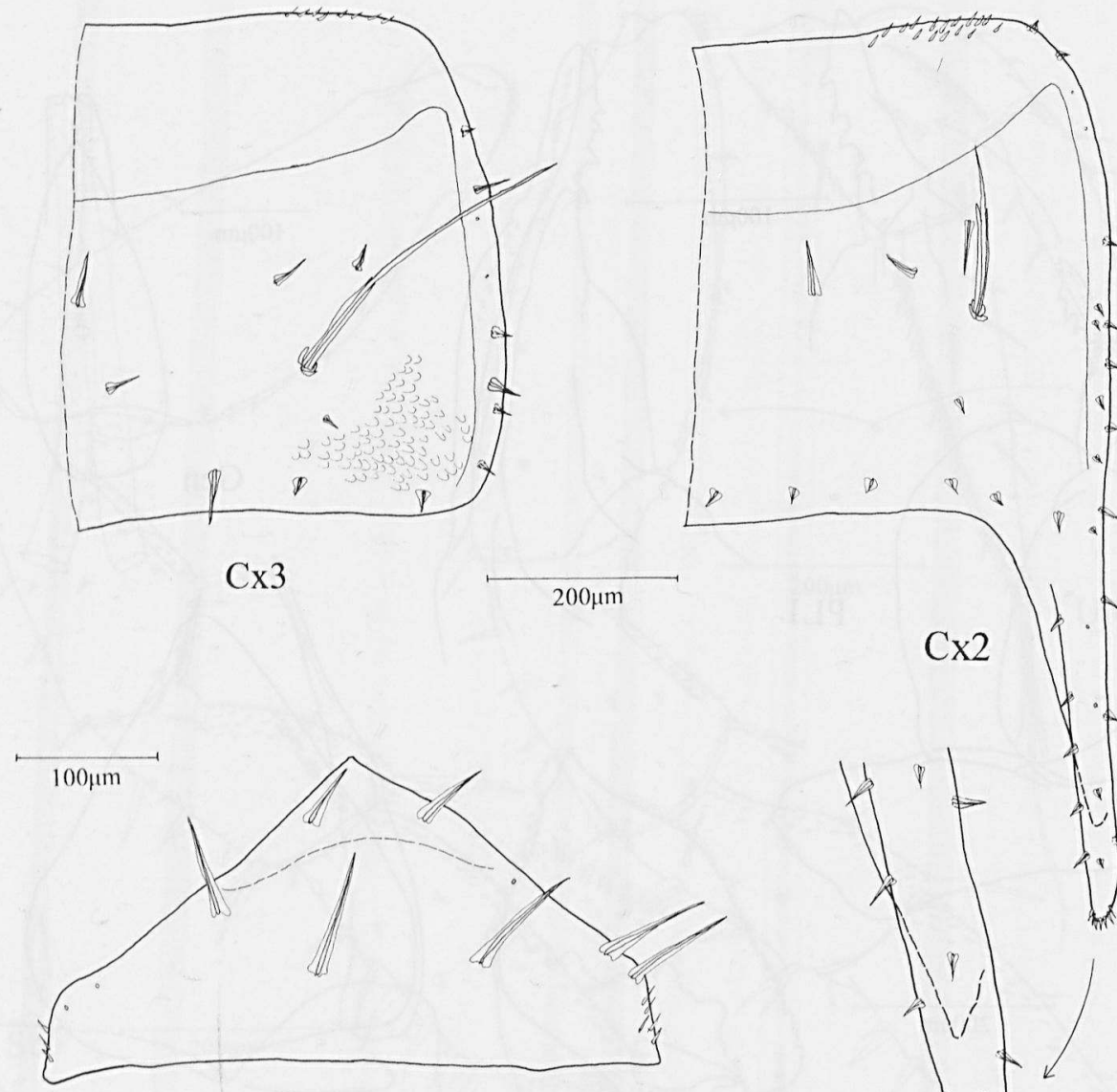

Tel

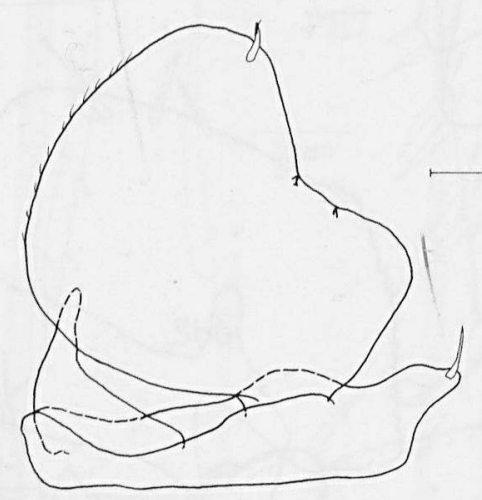

PL2

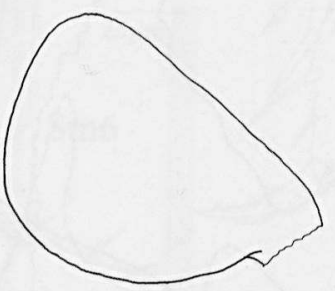

PL1

Fig. 11. Xiphoniscus mirabilis Vandel, 1968 Lectotype male 4.5mm. Cx2 male coxal plate II; Cx3 coxal plate III, PL1-2 pleopods 1 and 2 (paratype female $4 \mathrm{~mm}$ ); Tel pleotelson.

dorsally inserted on coxal plate IV, gland pores lacking (Fig. 6, Cxp).

Sexual dimorphism: Unique among the known Oniscidea males show differentiated coxal plates
II: laterocaudal edge prolonged, covered with tricorn-like setae (Fig. 11, Cx2) in fully adult specimens reaching distal end of pereionite IV (Vandel 1968). 
Pleon: Retracted from pereion, with rather inconspicuous neopleurae of plènites 3 to 5 , pleonites covered with tricorn-like' setae, pleotelson with fairly straight lateral margins, bearing some flagelliform tricorn-like setae (Fig. 11, Tel).

Antennula: Resembling antennula of Prosekia Vandel, 1968 with apically two, medially 6 aesthetascs, sets of aesthetascs well separated from each other, (Fig. 6, An1).

Antenna: Peduncle covered with tricorn-like setae and some sensory spines, length ratio of peduncular articles $1: 2: 2: 3: 4$, flagellum composed of three joints, articles 1 and 2 subequal in length, distal article almost twice as long, as the apical organ (Fig. 6, An2).

Mandible: Pars intermedia with few coniform setae and one or two penicils on right and left mandible, respectively, molar penicil consisting of prominent and three shorter branches, distally additional plumose seta (Fig. 7, Mdl/r).

Maxillula: Medial endite without apical tip, two rather slender penicils, lateral endite apically with $4+4$ teeth, inner set with cleft apices, lateral fringe consiting of strong trichiform setae (Fig. 7, Mx1).

Maxilla: Medial lobe of half the breadth of lateral lobe, apically bearing about eight cusps, lateral lobe with slightly sinuous rows of tiny trichiform setae, laterally some pectinate scales (Fig. 7, Mx2).

Maxilliped: Basis with sulcus lateralis and scattered tricorn-like setae, endite with two teeth on laterodistal edge, strong tooth caudally, rostral surface bearing knob-like penicil and setal tuft, palp with rather long lateral setae, proximal setal tuft reduced to single seta, medial tuft composed of about 5 setae, seemingly only medial spine of proximal article present (Fig. 7, Mxp).

Pereiopods: Slender appendages with rather short propus (Figs. 8/9, PE1-7), carpus and propus of pereiopod 1 with antenna-grooming brush, ornamental sensory spine with serrate double fringe (Fig. 8, Sc1), propus with longitudinal rows of tricorn-like setae, dactylus with short inner claw, dactylar seta simple (Fig. 8, Dac).

Sexual dimorphism: Obviously no sexual differentiation save the female pereiopod 7 ischium with less tricorn-like setae.

Pleopods: Exopods of pleopods 3 and 4 almost obliquely rectangular with four to five sensory spines laterally, exopod 5 pointed, bearing two sensory spines laterally, laterodistal hairlike setae inserting on slight protrusions, endopods of pleopd 3 and 4 bilobate with lobes acute, endopod obliquely quadrangular with distal margin lobate (Figs. 10/11, PL1-5).

. Sexual dimorphísm: Male pleopod 1 exopod almost circular, endopod complex, basal half rather stout, distal part narrower, apex bent laterally, acute, rostral surface with four lateral teeth directed proximally, caudally bearing medial row of short spines running from apex proximally, terminating about half way along the length to interlocking area with genital papilla, interrupted in its middle. Pleopod 2 exopod almost evenly triangular with two sensory spines laterodistally, endopod slender slightly bulbous at its apex.

Uropod: Protopod laterally grooved, another groove laterally of insertion of endopod to basis on caudal surface, endopod inserting proximally of exopod (Fig. 9, UR).

Genital papilla: Rather short as is pleopod 1 endopod, orifices surpassing ventral shield considerably (Fig. 10, Gen).

Remark: The adult male of Xiphoniscus mirabilis is easily identified by its prolonged coxal plates II, a charater which is unique among the Oniscidea. The morphology of the mandible seems to represent a more derived character state compared with the above mentioned genera since the molar penicil is composed of a strong branch and only three shorter branches. In Andenoniscus, Prosekia, and Erophiloscia the molar penicil is subdivided with up to 10 branches.

\section{Phylogeny within the Prosekia genus group}

There are several genera belonging to the monophyletic Prosekia genus group, which is characterised by the peculiar shape of the antennula with the stout distal article bearing two sets of aesthetascs, one distally composed of two aesthetascs and one medially of about 10 divergent aesthetascs. Another synapomorphy is a distinct lamellar structure of the apex of the male pleopod 1 endopod. Members of this monophylum are the genera 


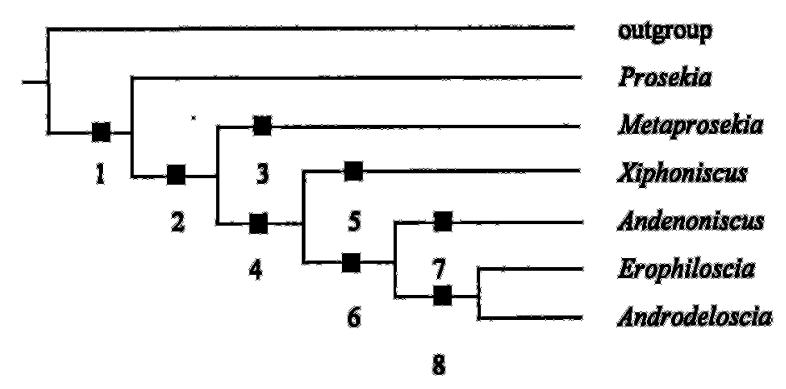

Fig. 12. Cladogram of the Prosekia genus group from South America reconstructed using Hennigian methods. Apomorphies supporting splits: 1, antennula with stout distal article, bearing erect subapical tuft of aesthetases separated from apical pair by a groove [antennula with pointed distal article, aesthetascs paired along medial margin]. 2, reduced size of maximally $5 \mathrm{~mm}$, compound eyes with up to 8 ommatidia looking randomly arranged [body length about $10 \mathrm{~mm}$, compound eyes with about 20 ommatidia arranged in four rows]. 3 , number of ommatidia reduced to 3, no distinct eye capsule; all noduli laterales in same distance to the lateral margin of coxal plates [distinct eye capsule encirrcling ommatidia; nodulus lateralis of coxal plate 4 more dorsally]. 4, noduli laterales flagelliform, sensillum surpassing cuticular scale more than two times; male pleopod 1 exopodite rounded [noduli laterales shorter, with cuticular scale as long as sensillum; male pleopod 1 distally pointed]. 5 , male coxal plate II caudally drawn out [coxal plate II rounded]. 6, male pleopod 2 endopodite more than twice as long as exopodite [male pleopod 1 endopodite slightly surpassing the exopodite]. 7, cephalothorax with linea supra-antennalis reduced, prominent lateral lobes present [with slight lateral lobes and linea supra-antennalis present]. 8, medial margin of male pleopod 5 exopodite straight for supporting pleopod 2 endopodite [with sinuous medial margin].

Prosekia Vandel, 1968 and Metaprosekia gen, n. from Venezuela, Xiphoniscus Vandel, 1968 from Ecuador, Erophiloscia Vandel, 1972 from Colombia and Peru, Andenoniscus Verhoeff, 1941 from Peru and Panama, and Androdeloscia Leistikow, 1999 which comprises most of the species formerly considered to represent members of Prosekia. The latter genus is found in the tropical regions of South and Central America from the Amazon basin to the cordilleras with its northernmost distribution in Guatemala (pers. obs.).

The reconstruction of the phylogeny was performed using the Hennigian principles of Phylogenetic Systematics with out-group comparison, determination of character homology and polarity, and subsequent tree construction using the maximum parsimony method. For out-group compari- son, Ischioscia martinae Leistikow, 1997, Littorophiloscia tropicalis Taiti \& Ferrara, 1986, and Deto echinata Guérin, 1836 were examined, characters identified as informative with respect of the reconstruction of the phylogeny are listed in table I with the plesiomorphic and apomorphic character states, the coded character matrix is given in table II. A bootstrap analysis of the results seems to be inappropriate since a non-computational method of tree construction was employed. The statistical tests like the Bootstrap test are made for big data sets, i.e. several thousand characters (for a detailed discussion see Carpenter 1992, 1996).

The monophyly of the Prosekia genus group is supported by the characters $06,07,14$. The structure of the antennula (06) is unique among the crinochete Oniscidea and the position of the aesthetascs on the distal article of the antennula (07) invariably differs from all other Crinocheta. The hyaline lamellae (14) are found in neotropical Oniscidea only among the representatives of the Prosekia genus group and thus are scored as apomorphies of this taxon, too. The next less inclusive taxon comprises Metaprosekia, Xiphoniscus, Andenoniscus, Erophiloscia, and Androdeloscia. Their synapomorphies are the small body size (01) and the different structure of the compound eye (04), which may be correlated to character (01) at least in part. It is interpreted as a synapomorphy in this case, because the reduction of body size must not lead to the reduction of ommatidia to less than ten and a loss of the arrangement of ommatidia in rows as recently demonstrated in the case of Ischioscia zebricolor Leistikow, 1999 (Leistikow 1999b).

The next more inclusive group separates Metaprosekia from the remaining genera. Metaprosekia is characterised by the autapomorphies (05) and (11) as discussed in the generic account. Xiphoniscus, Andenoniscus, Erophiloscia, and Androdeloscia are forming a monophyletic unit with the apomorphic character states noduli laterales flagellifrom (10) and male pleopod exopod rounded (13). The autapomorphies of Xiphoniscus are discussed in the generic account. The remaining three genera are characterised as a monophylum by the following synapomorphy: the male pleopod endopod 2 is more than two times longer than the exopod (15). 
Table I. Phylogenetically înformative characters used for cladogram construction indicating plesiomorphíc and apomorphic character state as a result of analysis of polarity by means of out-group comparison. Numbers in brackets indicate character number in Table II.

\begin{tabular}{|c|c|c|}
\hline Character (char, no) & Plesiomorphic State & Apomorphic State \\
\hline Body size of adult (01) & more than $10 \mathrm{~mm}$ & about $5 \mathrm{~mm}$ \\
\hline Linea supra-antennalis (02) & present & reduced \\
\hline Lateral lobes (03) & small & prominent \\
\hline Compound eyes (04) & ommatidia $>20$, arranged in four rows & ommatidia $<8$ \\
\hline Position of ommatidia (05) & ommatidia close to each other & ommatidia separated by pigment mass \\
\hline Antennula (06) & pointed distal article & stout distal article \\
\hline Aesthetascs (07) & paired along medial margin & $\begin{array}{l}\text { erect subapical tuft of aesthetascs separated from } \\
\text { apical pair }\end{array}$ \\
\hline Apical organ (08) & tuft of free sensilla & sensilla covered by cuticular sheath \\
\hline Nodulus lateralis (09) & absent & present \\
\hline Shape of Nodulus lateralis (10) & same length as tricoms & more than 2 times longer than tricorns \\
\hline Position of Nodulus IV (11) & more distanly from lateral margin & at same distance as other noduli \\
\hline Coxal plate II (12) & caudally rounded & caudally drawn out in the male \\
\hline Male Pleopod 1 exopod (13) & pointed & rounded \\
\hline Male Pleopod 1 endopod (14) & apically without hyaline lamellae & apically with hyaline lamellae \\
\hline Male Pleopod 2 endopod (15) & slightly longer than exopodite & more than twice as long as exopodite \\
\hline Male Pleopod 5 exopod (16) & medial margin sinuous & medial margin straight \\
\hline
\end{tabular}

Table II. Data matrix for recontruction of phylogeny of the Prosekia genus group. Character codes as indicated in table I; $0=$ plesiomorphic, $1=$ apomorphic character state.

01020304050607080910111213141516

\begin{tabular}{lllllllllllllllll}
\hline Deto & 0 & 0 & 0 & 0 & 0 & 0 & 0 & 0 & 0 & 0 & 0 & 0 & 0 & 0 & 0 & 0 \\
Ischioscia & 0 & 0 & 0 & 0 & 0 & 0 & 0 & 1 & 0 & 0 & 0 & 0 & 0 & 0 & 0 & 0 \\
Littorophiloscia & 0 & 0 & 0 & 0 & 0 & 0 & 0 & 1 & 1 & 0 & 0 & 0 & 0 & 0 & 0 & 0 \\
Prosekia & 0 & 0 & 0 & 0 & 0 & 1 & 1 & 1 & 1 & 0 & 0 & 0 & 0 & 1 & 0 & 0 \\
Metaprosekia & 1 & 0 & 0 & 1 & 1 & 1 & 1 & 1 & 1 & 0 & 1 & 0 & 0 & 1 & 0 & 0 \\
Xiphoniscus & 1 & 0 & 0 & 1 & 0 & 1 & 1 & 1 & 1 & 0 & 0 & 1 & 0 & 1 & 1 & 0 \\
Erophiloscia & 1 & 0 & 0 & 1 & 0 & 1 & 1 & 1 & 1 & 1 & 0 & 0 & 1 & 1 & 1 & 1 \\
Andeoniscus & 1 & 1 & 1 & 1 & 0 & 1 & 1 & 1 & 1 & 1 & 0 & 0 & 1 & 1 & 1 & 0 \\
Androdeloscia & 1 & 0 & 0 & 1 & 0 & 1 & 1 & 1 & 1 & 1 & 0 & 0 & 1 & 1 & 1 & 1 \\
\hline
\end{tabular}

Such an elongated endopod is found in some members of Chaetophiloscia Verhoeff, 1908, too. However, this correspondence is due to convergence, since the structure of the antennula, the male pleopod 1 endopod and the mouth parts differ in the taxa under consideration. A convergent evolution of an elongated endopod 2 is apparently more parsimonous than the reduction of the synapomorphies of the Prosekia genus group in Chaetophiloscia in favour of a sister group relationship of Chaetophiloscia and [Andenoniscus + Erophiloscia + Androdeloscia]. Among the genera Andenoniscus, Erophiloscia and Androdeloscia, the latter form a sister group with the synapomorphic shape of the male pleopod 5 exopod, which has a straight medial margin as a supporting structure for the flagelliform male pleopod 2 endopod. The triangular exopod 5 protects the fragile endopod 2 , and some further adaptations to this protective function can be found in both Erophiloscia and Androdeloscia: In Erophiloscia, where the endopods 2 are extraordinarily long, the pleopod 5 exopod is elongated, too. In Androdeloscia, which has shorter endopods 2 , a guide slot is present caudally on the medial margin of pleopod 5 exopod - a furrow covered by pectinate scales. The phylogeny of the about 15 species of Androdeloscia is discussed in Leistikow (1999a), new species and a phylogeny of Erophiloscia will be presented in Leistikow (in press b).

One can argue that the synapomorphic character - a supporting structure and even a guide slot is present in many taxa of Crinocheta, e.g., a SEMphotograph of the pleopod 5 exopod of Porcellio scaber Latreille, 1804 was presented by Hoese (1981: 153) and thus are useless for the reconstruction of the evolution of this genus group. The above given phylogeny stands in contrast to such an argument. Since there is good evidence for treating Erophiloscia and Androdeloscia as the most derived taxa in the Prosekia genus group and all the other representatives lack such a supporting structure, it is appropriate to conclude that is was not 
present in the ground pattern of this monophylum, or, it had to be reduced at least in the stem line of the group and re-evolved in Erophiloscia and Androdeloscia. A third scenario would be the reduction in Prosekia, Metaprosekia, Xiphoniscus and Andenoniscus independently. These scenarios are not apparently in agreement with the criterion of parsimony. Moreover, the closest relatives of the Prosekia genus group do not possess such a supporting structure, their pleopod 2 endopod is much shorter. The evolution of guide slots is correlated to slender and fragile pleopod 2 endopods as a functional unit and thus may have occurred several times in the evolution of crinochete Oniscidea. With respect to the structure of the exopod 5 in Erophiloscia and Androdeloscia, there are further synapomorphies: the lateral margin is concave instead of convex as in the members of Porcellio Latreille, 1804 and there are only two sensory spines present whereas in other taxa like Porcellio at least three sensory spines can be found. From the above statements, a sister group relationship of Erophiloscia and Androdeloscia is strongly supported.

\section{Acknowledgements}

The author is thankful to Prof. Dr. J.W. Wägele, Bochum for his support of this study and the possibilities to discuss several questions and Dr. C. Schmidt, Bochum for the loan of the Venezuela material. He is indebted to $\mathrm{Dr}$. $\mathrm{H}$. Dalens, Toulouse for the loan of the type material of Xiphoniscus mirabilis.

\section{References}

Carpenter JM. 1992. Random Cladistics. Cladistics 8: 147153.

Carpenter JM. 1996. Uninformative bootstrapping. Cladistics 12: 177-181.

Hoese B. 1981. Morphologie und Funktion des Wasserleítungssystems der terrestrischen Isopoden (Crustacea, Isopoda, Onísoidea). Zoomorphology 98: 135-167.

Leistikow A. 1998. Redescriptions of terrestrial Isopoda from Chile and Peru (Crustacea: Isopoda: Oniscidea) Spixiana 21: 215-225.

Leistikow A. 1999a. Androdeloscia gen. $n_{n}$, a new genus of South American terrestrial isopods with description of 13 new species (Crustacea: Oniscidea: "Philosciidae"), Rev. Suisse Zool. 106: 813-904.

Leistikow A. 1999b. New species of the genera Ischioscia and Andenoniscus from Panama (Crustacea, Isopoda). Stud. Neotrop. Fauna Environm. 34: 156-176

Leistikow A* (in press, a). A new definition for the genus Prosekia gen. n. from South America (Crustacea: Isopoda: Oniscidea). Spixiana.

Leistikow A. (in press, b). The genus Erophiloscia Vandel, 1972 - its phylogeny and biogeography, with description of three new species (Crustacea: Isopoda: Oniscidea). Spixiana.

Vandel A. 1952. Etude des isopodes terrestres récoltés au Vénézuela par le Dr. G. Marcuzzi, suivie de consíderations sur le peuplement du Continent de Gondwana. Mem. Mus. Civ. St. Nat. Verona 3: 59-203.

Vandel A. 1968. Isopodes terrestres. In: Leleup $\mathrm{N}$ and $\mathrm{J}$, ed. Mission zoologique belge aux hles Galapagos et en Ecuador. Resultats Scientifiques 1: 37-168.

Vandel A. 1972. Les ísopodes terrestres de la Colombíe. Stud. Neotr. Fauna Environm. 7: 147-172.

Verhoeff KW. 1941. Landisopoden. Inx Titschack E, ed. Die Fauna Perus. 1: 73-80.

Received: 5 July 1999 